\title{
Unlikely hikers? Activism, Instagram, and the queer mobilities of fat hikers, women hiking alone, and hikers of colour.
}

Accepted 11/11/2019 for publication in Mobilities.

\author{
Dr Phiona Stanley \\ Edinburgh Napier University
}

\begin{abstract}
This paper investigates a nascent, primarily online community of so-called 'unlikely hikers', united in the premise that hiking is good for everyone's mental and physical health and that diversity can and should extend to outdoor spaces including national parks. However, the ways in which hikers have hitherto been represented in outdoors media, advertising, and wider social imaginaries present potent barriers to participation. The paper traces the discursive origins and positioned ideologies of 'the outdoors' in former British settler colonies, particularly the USA, showing how national parks maintain legacies of frontier colonialism and default understandings of legitimate outdoorspeople as necessarily White, able-bodied, straight, and male. These legacies are then traced through four years of online ethnographic data (2015-2018), comprising multimedia narratives offat hikers, solo women hikers including lesbian women, and hikers of colour as they relate their outdoor experiences on Instagram and related podcasts, blogs, and magazine articles. The discussion is theorized using Holman Jones and Harris's notion of queering and Urry's mobilities paradigm, and 'queer mobilities' is proposed as part of an activism and amplification aimed at queering the trail both within and beyond academic spaces.
\end{abstract}

Keywords queer mobilities, embodiment, outdoors, hiking, representation, Instagram

\section{Introduction}

Walking is enjoying a moment. A clutch of recent books describes its restorative, meditative, and even transformational power (e.g. Kagge 2018; O'Mara 2019; Winn 2018), and Routledge recently published a 418-page International Handbook of Walking (Hall, Ram, and Shovel 2018). To those interested in walking-and an outdoors lifestyle more broadly-such publications may seem comprehensive.

However, across hundreds of thousands of words, only one mention is made of fatness and walking, and it is this: on page 259 of the Handbook, 'Adrian', a research participant, says he walks as much as possible 'to stop myself getting too fat' (Finnie, Wiseman and Ravenscroft, 2018)'. Seemingly, walking-let alone hiking-is not for all human beings simply and equitably to enjoy. Instead, for those who are obese, walking exists not for adventure or self-actualisation or wellbeing. For these unfortunates, walking is framed as a panacea. The editors provide a table that inversely correlates high levels of walking with 
low levels of obesity (Hall, Ram, and Shovel 2018, 4), and return, in the conclusion, to the notion that 'active travel, such as walking and cycling, is a significant contributor to reducing obesity' (ibid, 406). So, while walking is a source of redemption, enjoyment, meaning, and challenge for everyone else, this does not seem to include those whose bodies deviate from the supposed norm. For them, walking exists primarily as a means of losing weight.

This paper problematizes that notion. It investigates a nascent, primarily online community of so-called 'unlikely' hikers whose presence on hiking trails and whose activism online contests mainstream representations in outdoors media, advertising, and social imaginaries. Such activism also challenges the lazy and uncritical reproduction of such assumptions in some academic spaces, such as the International Handbook of Walking.

'Hikers' are defined here as anyone walking - and often camping out along, and sometimes rock scrambling over - non-urban, non-paved trails for the purpose of recreation rather than purely transportation. This may be for a few hours ('day hikers'), a few days ('section hikers'), or for weeks or months at a time ('long-distance hikers' or 'thruhikers', the latter of whom walk long trails such as the Appalachian Trail in a single hiking season). Jenny Bruso, of Unlikely Hikers, based in Portland, Oregon, writes:

What is an unlikely hiker? It's ironic, tongue-in-cheek, reclamatory. There is nothing unlikely about wanting to enjoy and explore nature. It's one of the most natural things any of us can do. Yes, the outdoors and public lands belong to all of us and sure, no one is getting a handwritten invitation to our National Parks and trailheads, but exclusion isn't always verbal. A lot of the time, it's about representation ...I was so tired of seeing the same kind of person on seemingly every social media-based hiking community. The image of the outdoor adventurer is White, thin, 'fit' and straight-looking. Often, moneyed (read: top of the line gear). Often, a man. The typical woman featured fits an even narrower set of guidelines. ...Unlikely Hiker encompasses anyone who doesn't fit that image. Bigger body types, people of color, queer, trans, gender nonconforming folks, differently-abled people and so on. The people you don't see in the outdoorsy ads. (Bruso, n.d.)

In terms of what this means in practice, Carrot Quinn (2018) - activist, author, and longdistance hiker, also USA-based-writes:

The hiking community is made up primarily of White, straight, thin, cisgender, ablebodied folks with money...If you're a person of color, or fat, or transgender ...you can't just leave that at home. ...Hikers who exist within marginalized groups and create Instagram accounts and Facebook pages...to create community and support for each other endure near constant harassment from more privileged hikers who would rather not be inconvenienced by having to admit that these issues are real.

....There is no 'staying neutral', in these times. You're either rolling up your sleeves to help or you're part of the problem.

This paper investigates social media activism of counter-hikers, focusing on fat hikers, queer hikers, women hiking alone, and hikers of colour. It is also worth saying that the focus of this paper is the USA, although comparisons are drawn with other former British settler colonies (e.g. Australia, Canada, and New Zealand). The reason is that, as Cooper (2009) notes of fat activism/fat studies more generally, US voices predominate. Sadly, this is also true of online 'unlikely hiker' activism, which, although increasingly engaged with minorities and Indigenous people within the USA, remains stubbornly oblivious to experiences without. As a result, for instance, when Jenny Bruso (2019) writes a guide to plus-size hiking gear, the 
products described and linked are easily available only in the USA. So, although the writer of this paper is neither US-American nor US-based, the activism examined here is US-centric.

\section{Theorizing queer mobilities}

The mobilities paradigm is predicated not just on the nuts and bolts of getting around but also on the imaginaries that undergird movement. Urry (2007) describes mobilities systems including the practical -e.g. buses and ticketing-but also the intangible. Within such systems, there may be either affordances (enablers of mobility) or constraints (restrictors of mobility), and whether a given person's mobility is afforded or constrained derives from social scripts. Mobilities, then, are affected by normative notions of who is, or is not, a legitimate beach goer (e.g. Small 2017), skier (e.g. Harrison 2013), swimmer (e.g. Harjunen 2019), tourist (e.g. Carter 2008), or hiker (this paper). While practical affordances certainly affect hiking mobilities -camping gear is expensive, for example, and it is difficult to source specialist plus-size clothing-the focus of this paper is intangible affordances/constraints.

Powerful normativities operate within intangible systems of mobilities, affecting what we expect a 'hiker' or an 'athlete' to look like (e.g. Burns-Ardolino 2018) or how a Handbook of Walking might engage with obesity. And then there is the critical pushback. In proposing the term 'queer mobilities', this paperdraws on Holman Jones \& Harris's (2018) book-length study of 'queering', which cites Ahmed's (2006, 67; 161) tracing of the etymology of 'queer' from notions of cross, adverse, and oblique and Butler's (1993, 220) depiction of queerness as a 'collective contestation, the point of departure for a set of historical reflections and future imaginings'. Queerness, then, is about so much more than sexualities. It is about deviance from a social script. 'Queering practices' are those that disturb the order of things, causing us to notice, problematize, and perhaps rework the taken for granted. The second part of 'queer mobilities' draws on Urry's (2007) rejection of the necessity of a community's physical proximity and his post-humanist framing of social worlds as assemblages of humans, non-humans, artefacts, and systems.

For example, citing Simmel, Urry $(2007,24)$ describes the nineteenth century 'socialistic wholesale opening-up and enjoyment of nature' borne of constructing railways in the European Alps. Thanks to trains, a particular type of activity became widespread: 'leisure walking in the countryside' (77). But the means of getting out into the mountains are insufficient, alone, to push city dwellers, with their 'easy' lives (24) towards 'adventure, where the body might come to life' (25). Concurrently, it was necessary to reimagine nature itself. Having previously been constructed as the 'wildest, most barren and frightful of landscapes' (78; using the example of the English Lake District), imaginaries of nature shifted through 'theories of romanticism, the sublime, the picturesque and the performative'. Together, these assemblages explain 'why certain groups feel a burning desire to be by a given lake [or] up a mountain' (37).

But while tangible and intangible mobilities systems gave affordances to 'affluent men' (80) who began to go hiking, these men ineluctably brought along the baggage of their own 'social taste and distinction, ideology and meaning' (80). This perhaps explains why hiking, even now, maintains the hauntology (after Derrida) of masculine-coded, colonizing narratives such as 'munro-bagging' (i.e. conquering and counting off Scottish peaks; 85) and the 'cult of nature, puritanism and individualistic ideology' (85, citing Barthes' analysis of the Guide Bleu). So, although wilderness spaces are open to all, powerful imaginaries of exclusion construct the social meanings of hiking trails. Urry writes that places themselves become fixed, desired, and 'kodakized' (258) -or, in 2019 parlance, Instagrammed-but it is 
also the case that images of hikers themselves are produced and consumed in ways that either align with, or trouble, notions of legitimacy. Thus, there are normative ways of engaging with hiking mobilities (such as the Handbook of Walking), and then there are unlikely hikers and the queering of mobilities. This paper considers the latter.

\section{Unnatural 'nature'}

While 'wilderness' and 'nature' may be imagined as non-human spaces by definition - the antithesis of cities, perhaps - national parks (in general) and hiking trails (in particular) are assemblages produced by social semiotics that are entirely man-made (in the sense both of being socially constructed but also in the sense of being imbued with patriarchy). This is what Cronon (1996) calls 'the trouble with wilderness'.

Wilderness ideologies can be traced to the nineteenth and early twentieth century colonial expansion of what began as British settler colonies. However, this expansion coincided with threats to the identity of settler societies themselves, and to notions of racial 'purity', in particular, as a result of immigration. In the USA, for example, between 1870 and 1920, over 26 million new migrants arrived, an annual figure that would not be equalled until the 1980s (Kosek 2004). Concurrently, from the 1850s, primarily in response to Chinese immigration, the (as yet unfederated) Australian colonies barred non-White immigration. So, while the expansion of the settler colonies was billed as a 'civilizing' mission in relation to the Indigenous people that were murdered and displaced, this coincided with a crisis of racial purity. One solution was the setting aside and preservation of land separate from 'civilization'. Ray (2009, 259) writes:

$[A]$ crisis of white bourgeois identity that drove men into the wilderness was also a crisis of masculinity, gender, and sexuality. In the Victorian era, 'civilization' became understood as 'feminizing' because of unprecedented immigration, which turned the city into a socially 'unhygienic' space. Wilderness parks were a response to a perceived 'crisis of masculinity'...the appeal of the aesthetics of a sublime, mountaintop transcendence could only be appealing (or accessible) to men in such a context.

As part of this discourse (after Fairclough 2003), the first national parks in the British settler colonies were founded: Yellowstone National Park (1872, USA), Royal National Park (1879, Australia), Banff National Park (1885, Canada), Glacier and Yoho National Parks (1886, Canada), and Tongariro National Park (1887, New Zealand). But there was nothing 'natural' about these re-wilded spaces previously inhabited by displaced people. Powerful ideologies were at work (Mar 2010; Spence 1999).

\section{Gender and the outdoors}

Just as the outdoors itself is not 'natural', there is nothing 'natural' about the ways in which outdoor magazines, advertising, and other media portray legitimate outdoorspeople in very specific ways: White, male, straight, muscular, and able bodied. In contrast, non-White, female, queer, fat, disabled, and other deviant bodies are rarely represented at all (Weatherby and Vidon 2018). And where women are included, they are usually pictured caring for family in campgrounds and occupying passive roles such as watching men read maps or put up tents (McNiel, Harris, and Fondren 2012). Such images reinforce men's roles but they also reinscribe heteronormative expectation s that women are mainly wives and mothers. Further, in portraying men and women as the only type of outdoorsy couple 
(including hand-holding and sleeping-bag-sharing couples), outdoor media portrayals erase queerbodies.

Connell's gender order theory (2005) helps explain the construction of women's and queer bodies in outdoor spaces. Hegemonic masculinity critiques the ways in which men's dominant positions are legitimized and the ways in which these normalize women's subordination. Accordingly, a woman who performs femininity in heteronormative ways (e.g. observing and following men as they do outdoorsy things) may be seen as an acceptable foil to masculinity, even as the performer is irreducibly constructed as lesser because of her actions. However, there is little conceptual leeway for women to imitate 'masculine' ways of being. These might include traits like strength, independence, and adventurousness: going alone or putting up the tent herself, forinstance. The two possible readings of such a behaviour are eitherinadequacy (when compared to a feminine script) or incongruity (when compared to a masculine script).

Women may also be frightened of going alone. Trimble $(1994,60)$ writes: 'Cultural barriers and fears keep many of our daughters away from the woods...women may crave solitude but many fear being alone on the landscape.' Similarly, Chasteen (1994) found that almost all her women participants would never hike alone because of feelings of vulnerability and isolation. Specifically, they were worried about being attacked by men.

\section{The unbearable Whiteness of hiking}

Related to imaginaries of women hikers as legible only in relational, heteronormative ways, Carter (2008) cites 'racial spatiality' as a theoretical framing that helps explain the relative paucity of Black hikers in the USA. This is the notion that all bodies, necessarily racialized, are constructed as belonging or not belonging in given social spaces. Racial spatiality is policed-sometimes literally-by boundary-marking, including the intangible but very real 'critical White gaze' (279). Lanham (2016, 151-155) exemplifies this in 'Birding while Black', a memoir of his work in the rural US South for the Department of Natural Resources:

$[\mathrm{H}]$ ere I am on stop number thirty-two of the Laurel Falls Breeding Bird Survey route: a large black man in one of the whitest places in the state [of South Carolina], sitting on the side of a road with binoculars pointed toward a house with the Confederate flag proudly displayed. ...My mind plays horrificscenes of an old black-and-white photograph -gleeful throngs at a lynching party. ...The pendulant, black-skinned guest of dishonor swings anonymously, grotesquely, lifelessly....Riding on an old logging road [on the way to a job], we met another truck. ...[The] men stared, heads slowly swiveling. Their looks bored through the windshield and wrapped themselves around my throat. ...[Then] the truck made a three-point turn for the only reason I could imagine: they'd decided they didn't want us back there. My stomach knotted.I wondered how long it would take the authorities to recover our decomposing corpses...I was questioning whether following my outdoor passion was truly worth it. This visceral hauntology is informed by symbols such as the Confederate flag, which remain potent reminders of a not-so-distant past.

Representation also matters. Frazer and Anderson (2018), analysing thousands of US-American outdoors magazines' photographs, found that more than $97 \%$ of images were of White people. Further, even where non-White people were represented, they occupied supporting, less risk-taking roles, such as being led rather than leading group activities.

It is therefore perhaps unsurprising that White men have long been 'default' outdoorspeople. Kosek (2004) traces historical discourses of racial purity in the outdoors 
and the conceptualization of a 'new, Anglo-Saxon, fundamentally masculine, American stock' (133). He critiques John Muir — he of bumper stickers like 'The mountains are calling and I must go' - tropes, even today, of an 'outdoorsy' identity:

[C] ontemporary fears and attitudes about race...led [Muir] to conclude that not everyone belonged in his beloved mountain cathedrals. Muir wrote disdainfully about the 'Chinaman' and 'Digger' Indian....and about the lack of appreciation on the part of the Hispanic herders for the majestic grandeur of the mountains....[T]his type of 'pure', 'natural' space, created by the elimination of Native Ame ricans and others who were deemed to have 'no right place in the landscape' became the basis for the national park system in the United States (137-138).

It is out of such exclusionist social imaginaries that outdoor subjectivities were born.

\section{Embodiment and the outdoors}

It is not only women and POC who are excluded from social imaginaries of the outdoors. There is also the question of embodiment. Ray (2009: 259-260) writes:

[C]ontemporary adventure culture prizes the 'fit' body: able, muscular, young, and male....To the extent that engaging in adventure culture has become a reflection of environmental sensibility, bodies that do not fit this model are deemed unenvironmental. Extending Progressive era links between the body, social hygiene, and the wilderness encounter, contemporary adventure culture equates physical fitness with environmental correctness.

This is to say that, on the one hand, individual wellbeing and bodily fitness, and, on the other, the wellbeing of 'the wilderness' can be seen as metonymic: the wellbeing of the individual body and the wellbeing of nature may be mutually metaphorical. 'Healthy parks, healthy people,' proclaim frequent signboards in US National Parks, suggesting that (seemingly) unhealthy people somehow pollute the sanctity and 'health' of the park itself. This suggests that deviant bodies do not belong on hiking trails, and a particular object of censure and disdain, discussed in this paper, is fat bodies.

A limited literature exists on fat mobilities. Small and Harris (2012), Lloyd (2014), and Harjunen (2019) examine fatness and mobilities, through lenses, respectively, of air travel, Western transnationalism, and public exercise spaces. Citing a 2015 discussion in Finnish media, sparked by two normative-bodied women observed mocking a 'severely overweight woman' climbing out of the pool after a swimming-based fitness class, Harjunen concludes:

The cultural (hyper)(in)visibility of fat people who exercise reinforces the idea that exercise, especially in public, is a privilege only for those who already have fit and athletic bodies and want to maintain them. ...The space reserved for exercise is still not inclusive enough and the presence of non-normative body types is perceived as undesirable.

Comparably, Small and Harris (2012) analyse discourses of air travel experiences, concluding that norms of obesity-as-moral-failure framed within a neoliberal paradigm of individual responsibility predominate. While calling for alternatives, they do little to acknowledge fat people's attempts to rework the narrative for themselves. There is little queering, therefore, of fat mobilities. In contrast, Lloyd (2014) makes the case for critical geographies of body size, writing that fat identities are necessarily fluid and acknowledging that 'being fat is experienced, narrated and understood differently by different people' (123). Some agency, here, is accorded to fat people. However, the focus remains the effects of obesity discourses on fat people. Again, the emphasis is on the attributional aspects of identity. 
So, while fatness and mobilities come together in identity work that is 'fluid' (to use Lloyd's word), it is a very different kind of 'liquid' identity to that explored by Gössling and Stavrinidi (2016), for example. Their study was of (body-normative) young people's social media (Facebook) identity performances and negotiations related to travel, including their online display of network capital. But whereas Gössling and Stavrinidi's participants agentively and strategically took up identity positions within privileged affordances, the fat mobilities papers cited describe constrained identities onto which meanings are inscribed. So, although fat mobilities scholarship has been undertaken, the emphasis has hitherto been on what is done to fat people (attributed identities) rather than what fat people do (appropriated identities). 'Unlikely hikers' activism moves beyond that framing, allowing fat hikers to engage in strategic, intersectional, and, above all, agentic identity work.

\section{On fatness}

The 'conversation' about obesity, between epidemiologist-led public health officials and media (the 'obesity alarmists') and countercultural obesity 'sceptics' (Gard 2011), is one in which harmful stereotypes are either reinscribed or contested. On the former side, media discourses portray fat bodies as '[P] hysical manifestations of individual (ir)responsibility and psychological dysfunction, [which] contributes to the ongoing stigmatisation of obesity' (Monson et al 2016, 524). As a result, fat people are pitied, pilloried, and patronised, often in what Gard $(2011,38)$ calls a 'shame-led public health agenda tinged with the fear of contagion' (e.g. the obesity epidemic). Counter positions, taken up by the discipline and journal of Fat Studies (as well as critical geographers and others, e.g. Andrews et al, 2012), critique this mainstream moral panic. Positions here include feminist critiques of body shaming as the 'extension of patriarchal science's centuries old persecution of women' (Gard, 44), which critique obesity alarmism as a coded morality, produced 'in an attempt to discipline people's desires, behaviours, relationships and subjectivities' (43). In contrast, critical discourses problematize stigmatizing, limiting, surveillance discourses of what fat bodies can do instead allowing for the possibility that fat people can be adventurous, physical, and - perhaps most subversive of all-happy.

In common with physical activity generally, hiking has the potential to offer health benefits to all, well beyond its putative role as a vehicle for weight loss (e.g. Andrews et al, 2012). However, mainstream narratives of fat embodiment have been shown to stigmatise and curtail fat people's enjoyment of physical activity-traceable in some cases to having been bullied in organised sports as young people-in which people erroneously come to believe that 'no matter how hard they try, they will not succeed' (Meadows \& Bombak 2019,138 ). Fat people's engagement in physical activity may thus be constructed as a form of penance in which fat 'exercisers are presumed to be recognizing their culpability in a fatphobic culture and trying to atone by taking responsibility for their burdensome bodies' (ibid, 139).

Why, then, with the weight of moral opprobrium directed towards non-White bodies, queer bodies, women who hike alone, fat bodies (and also, not discussed but worthy of further scholarly attention, ageing bodies, disabled bodies, working-class bodies, and non-hegemonic masculine bodies, for instance) - why hike at all? Why bother? The answer is because hiking enhances wellbeing. It lowers stress, lowers pulse rate, and lowers blood pressure. It enhances mood, promotes self-esteem, and combats mental fatigue (Barton et al, 2009; Park et al, 2010). Solo hiking seems to be particularly beneficial: Coble, Selin and Erickson (2003) found it offered autonomy, reflection, communion with nature, 
and a chance to experience 'flow', the latter of which Mills and Butler (2005) identify as most often experienced when hikers walk alone. In part, the benefits of lone hiking may be attributable to the spiritual dimensions of the experience, and Heintzman (2010) found that going alone is particularly important for women as it provides peace, tranquillity, an 'inner journey', and space for reflection.

\section{Positionality}

The study began as an accidental ethnography (after Poulos 2016), and it is worth exploring what brought me, this particular researcher, to this topic as my positionality necessarily affects my reading of the data and my take on its politics. As this is an interpretive study, my aim is not objectivity; arguably, this is impossible anyway, despite the assurances of putatively bias-free positivist research paradigms. Instead, I acknowledge and manage my interpretations through reflexivity (e.g. Pillow 2003), part of which is being explicit here.

In June 2012, somewhat burned out after two years' overwork in early-career academic jobs in Australia, I undertook my first solo, multi-day hike, the Thorsborne Trail, on Hinchinbrook Island, a national park in Queensland. I'd hiked and camped before - on overnight trips with friends and day hikes alone- but this was my first multi-day solo hike. I loved it. It was challenging as it was relaxing, spiritual as it was physical. Entirely focused on what I was doing, my mind found a 'flow' in which time slid by.

Although I didn't realise it initially, I came to understand that I had engaged in a deeply political endeavour. I say this because I am a fat, middle-aged woman (also White; also queer) and I walked alone, carrying all my food and gear, sleeping alone in the woods, and holding my nerve at signage warning of saltwater crocodiles around the island. Buoyed by this experience, I started hiking in earnest. But fat shaming was everywhere. Sometimes it was blatant and more often it manifested as subtle concern: 'Will you be ok? Have you trained for this? Do you know what you're doing? I'm worried about you' (Stanley, 2018). I ignored these voices, though, because I found hiking and camping, uniquely, had the capacity to quieten everyday life. I wrote in my trail journal:

I don't know who I would be if I didn't do this. It is me. I prove to myself I am capable. I may be fat, but, also, I am quite fit. ...Mainstream culture is a cacophony of voices telling me hateful things about my body. But out here those voices are so much further away...On this hilltop, I pause, and look around and remember who I am. Here, my body is simply my interface - the only one I will ever have - and it lets me walk on this red earth as humans have done here for fifty-thousand years [on the Larapinta Trail, in Australia's Northern Territory].

In March 2015, I opened an Instagram account to document my hiking and find community. One account I followed early on was Fatgirlshiking (active from May 2015), and in 2016 its founder messaged me to ask if I would like to be featured as an 'inspiring hiker' on their account. So it was that fatgirlshiking published a photograph of me -taken in the Blue Mountains of New South Wales, Australia- and the following caption, which I wrote: Hiking sustains me. It's exercise, yes, but mainly it's my version of a church or a mosque or a temple: headspace time with Mother Nature. When I hike, I'm more aware of what I can do than what I can't. Compare that to team and/or ball sports, which put me under pressure and thus put me off. And so, I hike. And camp. And breathe deeply and look at trees, stars, kangaroos. And I feel solucky.

(@fatgirlshiking, 21st Sept 2016) 
My positionality explains why I subscribe to the notion that it is possible to be physically fit while also being fat (and its corollary: that thin people are not ne cessarily fit or healthy). This is also why I use the word 'fat' to describe myself as opposed to 'overweight' or 'obese' or any other euphemistic or pseudo-medicalised term. Webb et al $(2019,157)$, discuss this politics of naming, citing the euphemism 'curvy', which may be used to 'avoid or deny the possibility of accepting oneself as fat' and which may, in turn, 'reinforce anti-fat bias'. Comparably, Summer Michaud-Skog, the founder of Fat Girls Hiking explains this point in an interview with Out in the Open, for Canada's CBC Radio (2018):

I feel like it's a political statement to call myself fat and use it in a positive way...It's the shame that society puts on people who are fat. The word itself doesn't necessarily have to be a shameful word. And I want to do whatever I can to ...to extract the stigma from that word.

\section{Methodology}

This paper is a netnographic study (Kozinets 2009) in which I analysed the multimodal content of sixty Instagram accounts (see Table 1) published from early 2015 to early 2019. During the period of the study, a few accounts became inactive and many more were established, so while sixty are listed in Table 1, and some ran throughout the four years, not all were continuously active.

Instagram is very different from Facebook in that most accounts are open access and networks do not rely on or replicate real-world friendships. Indeed, many accounts are all but anonymous, hiding behind a pseudonym (e.g. @Browngaltrekker) or using only a partial name (e.g. @Ashleysadventure). This means that Instagram accounts can 'follow' and 'be followed' based on common interests, discoverable through hashtags (keywords).

In a paper on the ethics of social media data in interdisciplinary research, Stevens, O'Donnell and Williams (2015: 157) conclude that considerations for using online social media data are: the distinction between public and private spaces, informed consent, and protecting data to ensure confidentiality and anonymity. For this reason, the data in this paper is exclusively drawn from public-domain Instagram accounts. Further, where identifiable names are given in the text, these are the names of people who have, themselves, published about their experiences, linking their publications to their Instagram accounts. For example, Vanessa Friedman writes in Autostraddle, an online magazine, and her Instagram account, @Vanessatakesphotos, links readers to her writing and thus her real name. Informed consent is assumed here as for any other publication cited.

However, for those accounts whose owners have not published elsewhere and whose user names make them identifiable (e.g. @janesmith: a fictional account, but an example of an identifiable one), comments and posts have been anonymized by changing user names, anonymising sources (e.g. where an individual's account is cited by one of the organisational accounts), and checking the searchability of utterances to ensure anonymity. Those accounts have been anonymized (e.g. @XXXX). However, most of the account names have been preserved for the just-as-compelling ethical reason of giving due credit to people doing activist work online. As most organizational accounts cited do not allow for identification of specific individuals, account names have, where possible, been preserved.

The accounts vary in type. Some are run by and are primarily about individuals while others are organisational accounts showcasing individuals who are diversifying the outdoors across one or more axis of identity. There are also those that organise group hikes, and some accounts blend one or more purposes. The accounts were purposefully sampled as 
they represent a range of perspectives and priorities around the notion of diversifying the outdoors. Broadly, they can be divided into accounts focusing on LGBTIQA++ visibility, fat acceptance, POC, and women in the outdoors including women who hike and camp alone.

The data was analysed using critical discourse analysis (Fairclough 2003) and visual methods in ethnography (Pink 2014). It is important to note that these are qualitative methods and no attempt was made to produce a quantitative account of the number of instances of a given phenomenon. This is because the accounts can not be representative of anything but themselves and any attempt at statistical analysis would be flawed due to the impossibility of representing from sample to 'population'. However, the purpose of this study is not to index or catalogue a phenomenon. To do so would be both impossible and also less useful than the present study, whose aim is to shed light on the conceptual space.

In rendering the captions, posts, and comments from Instagram, I use the following conventions. The account name starts with the @sign, as it does when Instagram users address comments to one another, and square brackets indicate emoji, which are described using emojipedia.org descriptors. For example:

@XXXX I [five red heart emojis] the article! Something I needed to read in the process of loving my body and letting go of society's expectations. Thank you.

\begin{tabular}{|l|l|l|}
\hline 1. Adventurequeers & Kellybrushfdn & Sumrvalentine \\
\hline 2. Ashleysadventure & Latinooutdoors & Theblindhiker \\
\hline 3. Beinggreenwhileblack & Latinxhikers & Thegreatoutchea \\
\hline 4. Bitches_who_hike & Lotsafreshair & Theladyalliance \\
\hline 5. Blackgirlshike_officialpage & Melaninbasecamp & Theventureoutproject \\
\hline 6. Blackgirlstrekkin & Nativewomenswilderness & Unlikelyhikers \\
\hline 7. Browngaltrekker & Naturechola & Vanessatakesphotos \\
\hline 8. Browngirlonthenst & Nerdie_hiker & Wanderlustier_hz \\
\hline 9. Brownpeoplecamping & Normaltonomad & Wanderwomanoutdoors \\
\hline 10. Carrotquinn & Nonbinarynomads & Wehikecalifornia \\
\hline 11. Curvykilicrew & Oshiehikeeatcamp & Wearehikertrash \\
\hline 12. Diversityinadventure & Outdoorafro & Wheelchairtraveling \\
\hline 13. Dykes_on_hikes & Outdoorasian & Wilderbound \\
\hline 14. Escapingyourcomfortzone & Pattiegonia & Womenontheroad \\
\hline 15. Fatgirlshiking & Queernature & Womenwhoexplore \\
\hline 16. Fatgirl.hiking & Queerquechua & Womenwhohike \\
\hline 17. Fathikingclub & Rahawahaile & Wonderfulwildwomen \\
\hline 18. iamlshauntay & Secondchancehiker & XXXX* \\
\hline 19. Indigenousgoddessgang & Sheexplores & YYYY* \\
\hline 20. Jennybruso & Summitwithin & ZZZZ* \\
\hline
\end{tabular}

Table 1: Instagram accounts analysed for this study

\section{Findings and discussion: Legible diversity}

With 288,000 and 160,000 followers respectively, @womenwhohike and @sheexplores are the biggest Instagram accounts studied, and similar, women-focused content is available from @wonderfulwildwomen, @theladyalliance, among many other accounts. In centring women in the outdoors, these accounts are somewhat counter-cultural, although the diversity on display is primarily gender (and even then, gender goes unproblematized as a 
binary; no standard notes on pronouns appear, for example). This means that the images in many ways replicate mainstream outdoors media except that women replace men. Most women on such sites are White, young, heterosexual, and conventionally attractive. A typical example (from one such site, not specified for the sake of preserving anonymity) is: When @BBBB found out she was pregnant with twins, she knew her time in the outdoors would change, but she also knew it wasn't going to end. She still gets out paddling and hiking whenever she can - with and without her boys. ... Here she is with [her son] on the summit of [name of mountain].

The accompanying on-trail image is of a smiling woman with long, blonde hair and a toddler. Another example, again anonymized, reads:

This is @CCCC, and she is currently hiking the [name of trail] ... It is a $3000 \mathrm{~km}$ (1850 miles) route stretching from [trailhead to trailhead] and was officially opened on [date]....Follow along on her journey as she continues on the wild and rugged terrain and landscapes of [the trail]...by giving her a follow at @CCCC \#thruhikerthursday The accompanying on-trail photograph is of a young, slender, blonde woman. Her personal Instagram account, linked from the group site, shows that she hiked with her boyfriend, to whom she refers as her 'Valentine' and with whom she describes sharing a tent. Thus, although these and other comparable Instagram accounts centre women -third-person singularverb forms describe their actions, giving them agency- these accounts barely trouble mainstream norms, in which women may legitimately access the outdoors accompanied by straight, male partners and/or children. Even John Muir's Sierra Club, founded in 1872, accepted women hikers on this basis (Solnit 2001, 153).

Somewhat less conventionally legible are Instagram accounts and posts of women hiking alone, and very few such images appear on the larger, women-focused accounts. This may explain - and be explained by - the opposition among some male hikers towards women who go alone. Citing the film Wild (2014), based on the memoir of the same name by Cheryl Strayed about her 1100-mile, 94-day section hike of the Pacific Crest Trail (PCT), Vanessa Friedman (2018) writes (emphasis in the original):

People in the long-distance hiking community love to talk shit about Cheryl Strayed. If you mention Strayed to a specific kind of hiker on the PCT, he'll be sure to let you know that she didn't even hike the whole trail, what a liar, and she's had sex, so you know she's a slut, and it's totally her fault that the PCT is overcrowded now, it's so annoying that all these dumb girls who have no idea what they're doing saw Wild and thought they could do a long trail. You'll find hikers talking this way on message boards and Facebook groups, which I expected because the internet can be a trash heap, but you'll find them talking this way on the trail too, which I guess I did not. So, although the presence of women on hiking trails is a form of diversity, there are still plenty of normative expectations about women's behaviour, and still plenty of sexism.

\section{Findings and discussion: Documenting oppression}

But many people, men and women, do hike alone. One hiker-type that often posts hiking selfies-suggesting and sometimes explicitly stating they are alone-are thru-hikers. They include@DDDD, @Ashleysadventure,@Vanessatakesphotos, @Rahawahaile, and @Wilderbound, among others. These particular hikers represent different axes of identity: they are variously fat, female, lesbian, POC, and/or hiking alone. All face myriad sociopolitical challenges besides the overarching practical challenges of hiking. 
@DDDD and @Rahawahaile have written extensively about their experiences of thru-hiking as African Americans. Sometimes, their most difficult experiences are off trail in so-called 'trail towns', the park-proximate settlements in which hikers resupply and rest. Over several months in 2016, @DDDD posted photographs of items for sale in trail towns. The first, from Gatlinburg, Tennessee, shows a joke-shop item called 'black face soap' whose packaging depicts a White woman looking appalled in a mirror as she washes her face and her skin turns black. @DDDD's caption reads: ‘Good-fucking-bye Gatlinberg'. The second photograph, taken outside a store in an unnamed southern town (captioned only 'Southern resupply'), shows a display of Confederate-flag souvenir items. As Lanham describes, cited above, the Confederate flag may evoke a great deal of fear among African Americans in the rural US South. There is also racism on the trail itself. Rahawa Haile (2017) describes one encounter:

As I'm moving along, a day hikerheading in the opposite direction stops me for a chat. He's affable and inquisitive. He asks what many have asked before: 'Where are you from?' I tell him Miami [Florida].

He laughs and says, 'No, but really. Where are you from from?' He mentions something about my features, my thin nose, and then trails off. I tell him my family is from Eritrea, a country in the Horn of Africa, next to Ethiopia. He looks relieved.

'I knew it,' he says. 'You're not black.'

I say that of course I am. 'None more black,' I weakly joke.

'Not really,' he says. 'You're African, not black-black. Blacks don't hike.'

I'm tired of this man. His from-froms and black-blacks. He wishes me good luck and leaves. He means it, too; he isn't malicious. To him there's nothing abnormal about our conversation. He has categorized me, and the world makes sense again. Not black-black. I hike the remaining miles back to my tent and don't emerge for hours.

Ashley Manning of @Ashleysadventure reports similar instances of perhapswell-meaning, but ultimately destructive, comments on her own 950-mile hike on the Appalachian Trail in 2018. Ashley describes herself in her Instagram biography as a 'plus-size outdoor influencer', and in her published writing (Manning, 2018), she describes the assumptions people make about fat women hiking:

I've been asked if I was lost, people asked me if I was training for the Appalachian Trail, and people assumed I was doing the trail to lose weight....Chances are, if you see a larger-bodied person hiking or kayaking or climbing, they probably are already aware of their bodies. They don't really need to be reminded. Let them live their lives. It took so long for me to accept my body and to accept that it can do anything I want it to do....My body is strong enough to crash the through rapids of the Chattooga River [Manning works as a river rafting guide]. For a month, I rowed a 2,000-pound boat on the Colorado River, through the Grand Canyon...We are not trapped in our bodies; they are our freedom.

And sometimes the on-trail aggressions are intersectional: sexist, fat-shaming, and homophobic. On quitting her PCT thru-hike, @Vanessatakesphotos (Friedman 2018) writes: I decided to stop hiking just shy of 500 miles in ...because of toxic masculinity and bro culture in the hiking community....Sometimes it goes like this: I stop at a water source and I ask a man I've been leapfrogging with all day [i.e. passing and being passed on trail] if he can scoot over so I can also have a place to sit in the shade. There isn't a lot of shade, but enough that I can sit too. He rolls his eyes and I, 
stupidly, make a joke about feminism and equality on the trail. He immediately snaps that the [gender] pay gap isn't real (what?) and then goes on a rant about feminists ruining everything....[T] hen he proudly tells me he's glad he's no longer at his desk job because a guy like him doesn't belong behind a desk. 'I should be out here, raping and pillaging the land,' [he says]. I open and close my mouth, but nothing comes out. By now several other folks have shown up - men and womenand they all hear his fucked-up announcement, but no one challenges him....Men make disgusting objectifying comments about women on trail, calling girls hot or ugly or fuckable or whatever makes them feel powerful in that moment, I guess....It can be like this, too: A sweet, athletic, blonde woman takes a liking to me and slows her pace so we can hike togetherfor a few hours. She admits she knows the trail is a boys' club, but she's used to it....'It's dumb how competitive everyone is about mileage,' she says, and I'm about to agree but she continues, 'I mean really, we should be most impressed with people like you! It's amazing that you're out here doing this!' I think she thinks she is being nice so I don't say, 'Wow, thanks for thinking it is so amazing that a fat, slow lesbian could be hiking this trail' ...lt's hot and I'm tired and fuck, I liked this woman, so I just say, 'Thank you.'

\section{Findings and discussion: Activism}

The existence, persistence, and insistence of the Instagram accounts cited suggest that oppression is not going unchallenged. But these are individual responses, and it is important to consider the more strategic interventions, too.

One example is @unlikelyhikers' routine inclusion of preferred pronouns for all its featured hikers. Many are cisgender (e.g. women using the pronouns she and her) but the visibility of all hikers' pronouns makes it easierfor non-binary hikers to use non-normative pronouns. @unlikelyhikers also routinely includes an Indigenous land attribution (for example: Location: South Fortuna Summit, San Diego, California. This is Kumeyaay+ land; 1 Feb 2017). Additionally, on @unlikelyhikers' posts, bracketed image descriptions appear for people with visual impairment. Thus, even those who are not, themselves, genderqueer, Indigenous, or visually impaired come to accept as normal this basic inclusivity.

Intersectionality is also acknowledged-indeed, arguably weaponized-when @OutdoorAsian posts a picture of the 'Latino Outdoors' group under their eponymous banner (10 Dec 2018), writing that the two groups had come 'together on the ancestral lands of the Samish, Skagit and Swinomish' to hike. @Blackgirlstrekkin cites US American civil rights activist Frannie Lou Hamer, writing 'Nobody's free until everybody's free' (4July 2018). On Instagram, constructed counter-assemblages -marginalized along various axes of identity-amplify each other's voices as they go out of their way to include one another.

Another way in which change occurs is by tapping into gay men's and, in particular, drag queen visibility, such as the mainstream popularity of Emmy-award-winning television show RuPaul's Drag Race. On Instagram, the most visible nexus between drag and hiking is @Pattiegonia, who debuted on Instagram in October 2018. The name a play on Patagonia, an outdoor-gear brand. Within ten months (to August 2019), @Pattiegonia had attracted over 176,000 followers. Writing in Outside Magazine, Perry (2018) describes her appeal:

[She's] the viral drag queen who dances atop mountains in six-inch-heeled boots. ...She's hilarious and captivating... [Pattiegonia's creator] doesn't do entire hikes in Pattie's boots, as the human ankle was not created for such a feat, but he always treks a portion in them....'There's a queen inside everyone,' he says. 'I think Pattie is 
the voice inside telling people they should just go for it. Live unapologetically....[The] ultimate goal is for Pattiegonia to inspire more people to spend time outdoors, particularly those who have historically been excluded from the outdoor community, including the LGBTQ community, people of color, and fat folks.

@Pattiegonia's popularity provides a platform for change-making at a practical as well as a representational level.In an Instagram post (10 April 2019), @Pattiegonia poses with an array of outdoor gear gifted by companies hoping for the visibility of product placement. Of this practice, called 'influencing', @Pattiegonia writes:

Since starting Pattie, I've been offered over $\$ 10,000$ of free gear. This pattern in 'influencer' culture where those who have plenty get more (and for free) seemed really off to me. And not because brands want to perpetuate a problem, but because they don't know a better option, so I decided to give them one. I replied and said, "Thank you so much for the offer but to be honest, I can afford what you're offering. So how about you give me the coat or backpack or hat or hell, even a few of them, and I can donate them or give them out group hikes instead?" And the responses ... I either 1. got ghosted instantly [i.e. the company never replied] 2. got told "hmmm well, that doesn't work for us bye. or 3. got told, "hell yes, what's your address?" These are the companies that have stepped up to the plate, not expecting anything in return. They didn't know this post was coming and they each deserve to be celebrated for what they've done and recognition for what it looks like to be a leader in a community. [posts links to 16 outdoor gear brands' Instagram accounts]. Other outdoor brands, where you at, queens!? I'd be happy to speak with you about how we can work together support the queer outdoor community and people that would gain a lot of access to the outdoors with your amazing products.

This post had, as of 13 August 2019, been 'liked' over 24,000 times. But of perhaps greater importance were the comments, and the ways in which they suggest this post may influence consumer, and thus corporate, behaviour:

@EEEE Amazing! Will definitely look at these brands first next time I need [to buy] something, they actually have the values that most claim to!

@FFFF Oh gosh, this post [hearts emoji] thank you for not being a typical influencer!!!! Also great list of companies!!!! Saving it for when I need to buy gear. @GGGG First of all, LOVE THIS you are such a genuine force of change and inspiration. Second of all, which company is that sleeping bag/quilt from?! I love it and want to support them.

@HHHH Can you share who fell into categories 1 and 2? I think they need to be held accountable.

Among the thousand-plus comments on this post, @Pattiegonia engaged with many other outdoor gear companies scrambling to offerfree merchandise to support unlikely hikers and (more cynically, perhaps) to associate themselves with the community support shown to the brands named in the post. Thus, although seemingly about merchandise, @Pattigonia's activism affects corporate narratives about diversity in the outdoors.

\section{Theorizing: Queering the trail}

Previous research has considered the mutually constitutive nature of intersectional identities and mobilities, and Mimi Sheller $(2018,45)$ notes that:

Humans seldom move alone, but almost always in ways that are dependent on others, connected with others, toward (or away from) others, and sometimes for or 
on behalf of others. It is not simply that social factors such as gender, race, sexuality, class, age, and ability shape our capacities and styles of movement in relation to other people, but rather that our capacities for movement shape our bodily experiences and identities within normative social orders and hegemonic mobility regimes.

For example, Kusters (2019) examined the contingent, moment-by-moment negotiation of deaf women's identities, which both shaped and were shaped by their mobilities in the context of taking Mumbai trains: the women were forced to choose a category of carriage, either for people with disabilities, or for women. So it is with unlikely hikers. Hiking while fat, and/or queer, and/or non-White, and/or as a lone woman: the difficulties are multiplicative rather than additive. Historically-rooted fear of racial violence, fat shaming, queerstigma, and concerns about transgressing legible gender roles work together, producing experiences that both shape and are shaped by queer hiking mobilities.

But some unlikely hikers do make it onto trails, and here the notion of intercorporeality helps make sense of how and why they do so, and how the experience in turn affects them. Macpherson (2009) reports on a study of sighted volunteers leading hikers with vision impairment, noting that the discursive and perceptual production of 'landscape' relies not just on the body but also on 'other bodies and our own embodied past' (1044), and that, drawing on Weiss, 'the experience of being embodied is never a private affair but is mediated by our continual interactions with other human and nonhuman bodies' (ibid). Being an unlikely hiker is similarly intersubjective, as it is interactional, a question of doing rather than only being. This is why queering is posited in its verb form. Per Gale (2014, 999):

Conceptualizing is always of and for the event; the emergence of the concept is always event/ful(I), in its becoming it is always part of event/uality; an eventu-ality that is alive in its vibrant and pulsating incomplete-ness. There is also a consistency in this plane of immanence in which concepts are always alive in their relationality to and with affect and percept [.]

When I first hiked 'alone', I searched out other 'fat girls hiking'. Other unlikely hikers, too, agentively use affective online communities to produce and mediate an experience that is negotiated and displayed as 'badass' embodiment (after Burns-Ardolino 2018) rather than incomprehensible, perhaps threatening, transgression. Thus, when @Ashleysadventure is fat shamed, she draws on her own embodied experience of river-raft guiding for legitimacy. Similarly, when @Vanessatakesphotos is gender-shamed, fat-shamed, and queer shamed, she reaches into a discourse of intersectional feminism to speak back to the 'bro' she encounters 'raping and pillaging the land' on trail. In each case, marginalization is countered by intercorporeality and by doing: recourse to past embodiment, to alternative discourses, and to community.

Unlikely hikers' mobilities, in turn, feed agentic narrative identities. The curation of online 'hiker' identities is a powerful stance and one from which several of the Instagram accounts have built influencer and community organising platforms aimed at effecting social change. Instead of accepting freebies in exchange for product placement, @Pattiegonia subverts the narrative of corporate responsibility, leaving outdoor companies scrambling to offerfree outdoor equipment and clothing to marginalized hikers across intersections of identity, thus, changing the tangible affordances landscape for those who cannot afford specialist gear.Jenny Bruso (@unlikelyhikers) and Summer Michaud-Skog (@fatgirlshiking) have each established inclusive group hikes and local hiking 'chapters' around the USA, 
within which they offer safe experiences to would-be unlikely hikers. They are thus changing the landscape of intangible affordances. Similarly, by widening hiker representation, the Instagram accounts cited work towards nudging at social imaginaries of what a hiker looks like; this, too, affects intangible mobilities affordances. These are all queering practices, part of mobility justice (Sheller, 2018), in which established norms are explicitly challenged.

\section{Conclusion}

This paper sheds light on those intangible mobilities systems that offer affordances (for some) and constraints (for others) in accessing the outdoors. As demonstrated, these draw on the founding ideologies of national parks and on the discourses of outdoor media, which tends to erase and/or limit the agency and visibility non-traditional outdoorspeople. By making the 'rules' of hiking trails visible and by explicitly pushing back, this paper has aimed to effect change.

Amplifying and theorizing work already occurring -online and on trails-is of paramount importance, and this paper brings these issues to the attention of a wider, academic audience. The fact that, as late as 2018, a scholarly Handbook of Walking can be published in which issues of equity are not front and centre suggests that there is a very great need for awareness of queer mobilities among scholars.

There is a clear need, too, for more empirical research, including that using walking methodologies (Springgay and Truman 2018) as both the means and the object of study.

Surveying Instagram is one contribution, but there is a need for research among both 'likely' and 'unlikely' hikers. As scholars come to understand and contest hiking as a microcosm of powerful normativities, we may perhaps begin to ameliorate the broader, negative effects on human wellbeing of restricting hiking trails only to a subset of humans: straight, affluent, normative-bodied White men.

\section{References}

Ahmed, S. 2006. Queer phenomenology: Orientations, objects, others. Durham NC: Duke University Press.

Andrews, G. J., E. Hall, B. Evans, and R. Colls. 2012. "Moving Beyond Walkability: On the Potential of Health Geography." Social Science and Medicine 75(11): 1925-1932.

Baldwin, A. 2009. "The White Geography of Lawren Stewart Harris: Whiteness and the Performative Coupling of Wilderness and Multicultural ism in Canada". Environment and Planning A: Economy and Space 41(3): 529-544. doi: 10.1068/a40110

Barton, J., R. Hine, and J. Pretty. 2009. "The Health Benefits of Walking in Greenspaces of High Natural and Heritage Value". Journal of Integrative Environmental Sciences 6(4): 261-278. doi:10.1080/19438150903378425.

Bruso, J. n.d. Unlikely Hikers. https://jennybruso.com/unlikelyhikers/

Bruso, J. 2019. "Winter layering for the plus-size hiker." Outside Magazine, Jan 25, https://www.outsideonline.com/2384121/plus-size-winter-layering

Burns-Ardolino, W. 2018. "Badass Athena triathletes: Athletic Performativity and Embodiment." Fat Studies (Latest Articles) doi:10.1080/21604851.2019.1546517

Butler, J. 1993. Bodies That Matter: On the Discursive Limits of 'sex'. New York: Routledge.

Carter, P. L. 2008. "Coloured Places and Pigmented Holidays: Racialized Leisure Travel." Tourism Geographies 10: 265-284. doi: 10.1080/14616680802236287.

Chasteen, A. 1994. "The World around Me: The Environment and Single Women". Sex Roles 31(5-6): 309-328. doi: 10.1007/BF01544591. 
Coble, T. G., S. W. Selin, and B. B. Erickson. 2003. "Hiking Alone: Understanding Fear, Negotiation Strategies, and Leisure Experience". Journal of Leisure Research 35(1): 122. doi: 10.18666/jlr-2003-v35-i1-608.

Connell, R. 2005. Masculinities ( $2^{\text {nd }}$ Ed). Sydney, Australia: Allen and Unwin.

Cronon, W. 1996. "The Trouble with Wilderness: Or, Getting Back To the Wrong Nature". Environmental History 1(1): 7-28. (no doi).

Fairclough, N. 2003. Analysing Discourse: Textual Analysis for Social Research. London: Routledge.

Finnie, K., T. Wiseman, and N. Ravenscroft. 2018. "Rambling On: Exploring the Complexity of Walking as a Meaningful Activity". In Routledge International Handbook of Walking, edited by C. M. Hall, Y. Ram, and N. Shoval, 253-263. Abingdon and New York: Routledge.

Frazer, R. L., and K. Anderson. 2018. "Media Representations of Race, Ability, and Gender in Three Outdoor Magazines: A Content Analysis of Photographic Images". Journal of Outdoor Recreation, Education and Leadership 10(3): 270-295. doi: 10.18666/JOREL2018-V10-13-9051.

Friedman, V. 2018. "Why I Got Off the Pacific Crest Trail." Autostraddle.com: First Person. https://www.autostraddle.com/the-pacific-crest-trail-has-a-toxic-masculinityproblem-why-i-got-off-trail-after-454-miles-instead-of-walking-all-the-way-tocanada-408954/

Gale, K. 2014. "Moods, Tones, Flavors: Living With Intensities as Inquiry." Qualitative Inquiry 20/ 8: 998-1004. doi:10.1177/1077800413513725.

Gard, M. 2011. "Truth, Belief and the Cultural Politics of Obesity: Scholarship and Public Health Policy". Critical Public Health 21(1): 37-48. doi: 10.1080/09581596.2010.529421.

Gössling, S. \& Stavrinidi, I. 2016 "Social Networking, Mobilities, and the Rise of Liquid Identities". Mobilities 11(5): 723-743. DOI: 10.1080/17450101.2015.1034453.

Haile, R. 2017. "Going it Alone." Outside Magazine, April 11.

https://www.outsideonline.com/2170266/solo-hiking-appalachian-trail-queer-blackwoman

Hall C. M., Ram, Y. and Shoval, N. Eds. 2018. The Routledge InternationalHandbook of Walking. Abingdon and New York: Routledge.

Harjunen, H. 2019. "Exercising Exclusions: Space, Visibility, and Monitoring of the Exercising Fat Female Body." Fat Studies 8:2, 173-186, DOI:10.1080/21604851. 2019.1561101

Harrison, A. K. 2013. 'Black Skiing, Everyday Racism, and the Racial Spatiality of Whiteness', Journal of Sport and Social Issues, 37(4): 315-339. doi: 10.1177/0193723513498607.

Heintzman, P. 2010. "Nature-Based Recreation and Spirituality: A Complex Relationship". Leisure Sciences 32: 72-89. Doi 10.1080/01490400903430897.

Holman Jones, S. \& Harris, A. 2018. Queering autoethnography. New York: Routledge.

Kagge, E. 2018. Walking: One Step at a Time. London: Random House.

Kosek, J. 2004. "Purity and Pollution: Racial Degradation and Environmental Anxieties". In Liberation Ecologies: Environment, Development, Social Movements edited by R. Peet and M. Watts, 125-165. London: Routledge.

Kozinets, R. V. 2009. Netnography: Doing Ethnographic Research Online. Thousand Oaks, CA: Sage Inc.

Lanham, J. D. 2016. The Home Place: Memoirs of a Colored Man's Love Affair with Nature. Minneapolis: Milkweed Editions. 
Lloyd, J. (2014) "Bodies over Borders: The Sized Body and Geographies of Transnationalism." Gender, Place \& Culture 21(1): 123-131, doi: 10.1080/0966369X.2013.791253.

Lovelock, K., B. Lovelock, C. Jellum, and A. Thompson. 2011. "In Search of Belonging: Immigrant Experiences of Outdoor Nature-Based Settings in New Zealand". Leisure Studies, 30(4): 513-529. doi:10.1080/02614367.2011.623241.

Manning, A. 2018. "I was Made for this Outdoor Life." Jul 252018. https://thetrek.co/appalachian-trail/was-i-made-for-this/

Mar T.B. 2010. "Carving wilderness: Queensland's National Parks and the Unsettling of Emptied Lands, 1890-1910". In Making Settler Colonial Space edited by T. B. Mar and P. Edmonds, 73-94. Palgrave Macmillan, London.

McNiel, J. N., D. A. Harris, and K. M. Fondren. 2012. "Women in the Wild: Gender Socialization in Wilderness Recreation Advertising". Gender Issues 29: 39-55. doi: 10.1007/s12147-012-9111-1.

Meadows, A and A. E. Bombak. 2019. "Yes, we Can (No, you Can't): Weight Stigma, Exercise Self-Efficacy, and Fat Identity Development." Fat Studies 8(2): 135-153.

Michaud-Skog, S. 2018. "Episode 17: Summer, Fat Girls Hiking”. Be Nourished (podcast). https://www.listennotes.com/podcasts/be-nourished/episode-17-summer-fat-girlsMOAk40d-gYB/

Mills, A. S. and T. S. Butler. 2005. "'Flow' Experience among Appalachian Trail Thru-Hikers". Proceedings of the Northeastern Recreation Research Symposium. http://www.americantrails.org/resources/benefits/flowexperAT.html

Monson, O., N. Donoghue, and R. Gill. 2016. "Working Hard on the Outside: A Multimodal Critical Discourse Analysis of 'The Biggest Loser Australia'”. Social Semiotics 26(5): 524-540. doi:10.1080/10350330.2015.1134821.

O'Mara, S. 2019. In Praise of Walking. London: The Bodley Head.

Out in the Open 2018. "Fat, Tattooed and on the Trail: Meet the Woman Changing What It Means To Be A Hiker". CBC Radio: Canada. https://www.cbc.ca/radio/outintheopen/community-creators-1.4898904/fattattooed-and-on-the-trail-meet-the-woman-changing-what-it-means-to-be-a-hiker1.4936548

Park, B. J., Y. Tsunetsugu, T. Kasetani, T. Kagawa, and Y. Miyazaki. 2010. "The Physiological Effects of Shinrin-yoku: Evidence from 24 Forests across Japan". Environmental Health and Preventative Medicine 15(1): 18-26. doi:10.1007/s12199-009-0086-9.

Patterson, I., S. Pegg and W. R. W. Omar. 2018. "Walking to promote increased physical activity." In The Routledge International Handbook of Walking, edited by C. M. Hall, Y. Ram, and N. Shoval, 274-287. Abingdon and New York: Routledge.

Perry, G. 2018. "Pattie Gonia Is the World's First Backpacking Queen". Outside Magazine, Nov 12, 2018. https://www.outsideonline.com/2363691/pattie-gonia-worlds-firstbackpacking-queen.

Pillow, W. 2003. "Confession, Catharsis, or Cure? Rethinking the Uses of Reflexivity as Methodological Power in Qualitative Research". International Journal of Qualitative Studies in Education 16(2): 175-196. Doi 10.1080/0951839032000060635.

Pink, S. 2008. Doing Visual Ethnography. Thousand Oaks, CA: SAGE Publications.

Poulos, C. N. 2016. Accidental Ethnography. New York: Routledge.

Quinn, C. 2018. "Intersectionality and Long-Distance Hiking". https://carrotquinn.com/2018/04/30/intersectionality-and-long-distance-hiking-thewilderness-is-not-an-apolitical-space-2/ 
Ray, S. J. 2009. "Risking Bodies in the Wild: The 'Corporeal Unconscious' of American Adventure Culture". Journal of Sport and Social Issues 33(3): 257-284. doi: 10.1177/0193723509338863.

Sheller, M. 2018. Mobility justice: The politics of movement in an age of extremes. London \& New York: Verso.

Small, J. 2017. "Women's 'beach body' in Australian women's magazines." Annals of Tourism Research 63: 23-33. DOI: 10.1016/j.annals.2016.12.006.

Small, J. \& Harris, C. 2012. "Obesity and Tourism: Rights and Responsibilities." Annals of Tourism Research 39(2): 686-707. DOI: 10.1016/j.annals.2011.09.002.

Solnit, R. 2001. Wanderlust: A history of walking. London: Verso.

Spence, M. D. 1999. Dispossessing the Wilderness: Indian Removal and the Making of the National Parks. New York: Oxford University Press.

Springgay, S. \& Truman, S. E. 2018. Walking Methodologies in a More-Than-Human World: WalkingLab. Abingdon \& New York: Routledge.

Stanley, P. (2018). Walking to Heal or Walking to Heel? Contesting Cultural Narratives about Fat Women who Hike and Camp Alone. In Questions of Culture in Autoethnography edited by P. Stanley \& G. Vass, 129-141. Abindgon \& New York: Routledge.

Stevens, G., V. L. O'Donnell and L. Williams (2015). "Public Domain or Private Data? Developing an Ethical Approach to Social Media Research in an Interdisciplinary Project." Educational Research and Evaluation, 21(2): 154-167. doi: 10.1080/13803611.2015.1024010.

Torabian, P. \& Miller, M. C. 2017. "Freedom of movement for all? Unpacking racialized travel experiences." Current Issues in Tourism 20(9):931-945. doi: 10.1080/13683500.2016.1273882.

Trimble, S. 1994. "A Land of One's Own". In The Geography of Childhood edited by G. P. Nabhan and S. Trimble, 55-75. Boston: Beacon Press.

Urry, J. 2007. Mobilities. Cambridge: Polity Press.

Weatherby, T. G., and E. S. Vidon. 2018. "Delegitimizing Wilderness as the Man Cave: The Role of Social Media in Female Wilderness Empowerment". Tourist Studies 18(3): 332-352. doi:10.1177/1468797618771691.

Webb, J. B., E. Thomas, C. B. Rogers, V. Clark, E. Hartsell \& D.Putz (2019) "Fitspo at every size? A comparative content analysis of \#curvyfit versus \#curvyyoga Instagram images". Fat Studies, 8(2): 154-172, doi: 10.1080/21604851.2019.1548860

Winn, R. 2018. The Salt Path. London: Penguin.

\section{Acknowledgement}

The author would like to thank Professor Paul Lynch and Dr Ken Gale, as well as anonymous reviewers, for supportive, insightful, and incredibly useful feedback on earlier drafts of this paper. 